\title{
Utilização da casca de café na alimentação de suínos nas fases de crescimento e terminação
}

\author{
Ângela Rocio Poveda Parra ${ }^{1}$, Ivan Moreira², Antonio Claudio Furlan², Diovani Paiano ${ }^{1}$ \\ Carina Scherer ${ }^{1}$, Paulo Levi de Oliveira Carvalho ${ }^{1}$
}

\footnotetext{
1 Pós-Graduação em Zootecnia da Universidade Estadual de Maringá. Av. Colombo, 5790, CEP: 87020-900, Maringá - Paraná

2 Departamento de Zootecnia - Universidade Estadual de Maringá, Av. Colombo, 5790, CEP: 87020-900, Maringá - Paraná.
}

RESUMO - Foram conduzidos dois experimentos com o objetivo de determinar os valores nutricionais das cascas de café melosa (CM) e seca (CS) e avaliar seus níveis de inclusão sobre o desempenho e as características da carcaça de suínos nas fases de crescimento e terminação. As cascas foram moídas em peneiras de 2,5 mm (CM2 e CS2) e 4,0 mm (CM4 e CS4). No experimento I, foram conduzidos dois ensaios de digestibilidade, utilizando 15 suínos machos castrados, com peso inicial de $45,7 \pm 4,12 \mathrm{~kg}$ e de $77,5 \pm 6,28 \mathrm{~kg}$ para as fases de crescimento e terminação, respectivamente. Os valores de ED (kcal/kg) para CM2, CM4, CS2 e CS4 foram 2.494, 2.498, 1.236 e 1.345. A CM apresentou valores de energia digestível (ED) superiores à CS; entretanto, a moagem não melhorou os valores de ED. No experimento II, foram utilizados 40 suínos híbridos comerciais com peso inicial de 33,42 \pm 0,53 kg e de 59,0 \pm 4,17 kg para as fases de crescimento e terminação, respectivamente. Foram avaliados cinco níveis de inclusão (0, 5, 10, 15 e 20\%) de CM4. Na fase de crescimento, o consumo diário de ração (CDR) apresentou diferença no último nível de inclusão (20\%) quando comparado à ração-testemunha (RT). Foi observada redução linear do ganho diário de peso (GDP) com o aumento dos níveis de inclusão da CM4. A conversão alimentar (CA) foi semelhante entre os níveis de inclusão e a RT. Na fase de terminação, houve redução linear do CDR com o aumento dos níveis de inclusão da CM4. Houve efeito quadrático para o GDP, que foi melhor no nível de inclusão de 8,43\%. Os valores de espessura de toucinho dos tratamentos com CM4 foram menores quando comparados à RT nas duas fases. Houve redução linear do peso de carcaça quente e peso de pernil nos níveis de inclusão. O rendimento de carcaça quente piorou com cada nível de inclusão em relação à RT. Os resultados sugerem que a CM pode ser incluída em níveis de até 5,0\% na fase de crescimento e 9,5\% na fase de terminação, por ser economicamente viável, sem prejudicar o desempenho, além de produzir carcaças mais magras.

Palavras-chave: alimento fibroso, características de carcaça, composição química, desempenho, digestibilidade, granulometria

\section{Coffee hulls utilization in growing and finishing pigs feeding}

\begin{abstract}
Two experiments were carried out to determine the nutritional values of sticky (SC) and dry coffee hulls (DC) and their effects on the performance and carcass quality of growing and finishing pigs. The hulls were ground in 2.5 mm (for SC2 and DC2) and $4.0 \mathrm{~mm}$ (SC4 and DC4). In Exp 1, two digestibility assays were carried out with 15 barrow pigs weighting $45.7 \pm 4.12 \mathrm{~kg}$ and $77.5 \pm 6.28 \mathrm{~kg}$ for growing and finishing phases, respectively. The digestible energy (DE) values (kcal/kg) for SC2, SC4, DC2 and DC4 were 2,494, 2498, 1,236 and 1,345. The values of the SC showed DE values superior to DC, however, the grinding process did not improved the DE values. In experiment 2, 40 crossbred pigs were used, averaging initially $33.42 \pm 0.53 \mathrm{~kg}$ and $59.45 \pm 0.14 \mathrm{~kg}$ in the growing and finishing phases, respectively. Five SC4 inclusion levels $(0,5,10,15$ and 20\%) were evaluated. In the growing phase, the daily feed intake (DFI) presented differences for $20 \%$ inclusion level when compared with control diet (CD). There was a linear decrease on daily weight gain (DWG) when DC4 increase on diet and F: G ratio was the same for CM4 inclusions and CD. In the finishing phase, there was a linear reduction of DFI with the increasing inclusion SC4 level. There was quadratic effect for DWG, which was better in the inclusion of $8.43 \%$. The backfat thickness values in SC4 treatments were lower as compared to CD in both phases. There was a linear reduction of hot carcass weight and ham weight in the inclusion levels. The hot carcass yielding worst in each inclusion levels as compared to CD. The results suggest that the inclusion up to $5.0 \%$ of SC4 in the growing phase and $9.5 \%$ in the finishing phase, because it is economically viable with no effect on performance, besides to produce lean meat carcasses.
\end{abstract}

Key Words: carcass traits, chemical composition, digestibility, fibrous feedstuffs, particle size, performance 


\section{Introdução}

A utilização racional dos diferentes tipos de ingredientes provenientes da agroindústria vegetal e animal na alimentação de suínos depende basicamente da composição química, digestibilidade e disponibilidade dos nutrientes, os quais, associados às exigências nutricionais, propiciam aos suínos adequado desempenho (Ferreira et al., 1997).

O Brasil, com uma agricultura de relevante importância, gera grandes quantidades de subprodutos agroindustriais, entre eles a casca de café, subproduto de elevada disponibilidade, que pode ser utilizado na alimentação de suínos, por ser um subproduto de baixo custo, possibilitando produção mais econômica de carne suína (Oliveira, 2001). A casca representa $40 \%$ do fruto maduro e retorna às lavouras de café como adubo orgânico ou perde-se por não ter utilização. Considerando a previsão de produção brasileira (CONAB, 2007) de 40,62 milhões de sacas para a safra 2006/07, estima-se a produção de cerca de 974 milhões de toneladas de casca de café.

Os tipos de casca de café resultam do grão colhido e do processamento. A casca de café melosa tem como principal característica, em relação à casca de café seca, a ausência do pergaminho, um componente fibroso, o que torna os nutrientes melhor aproveitados na alimentação de suínos, embora apresente altos teores de fibra e fatores antinutricionais (polifenóis, taninos e cafeína) que podem limitar sua utilização em função da baixa digestibilidade dos seus nutrientes (Oliveira, 2001).

O uso dos resíduos da cultura do café é limitado pelo conteúdo de fatores antinutricionais, como polifenois, taninos e cafeína, os quais interferem na aceitação do alimento e na absorção de nutrientes (Mehansho et al., 1987).

Na utilização de alimentos fibrosos para suínos, deve-se considerar que os efeitos nutricionais e fisiológicos da fibra dependem não só da quantidade de parede celular incorporada à dieta, mas também de sua composição química e estrutural e da forma como está fisicamente associada a outros nutrientes (Medeiros et al., 1988).

Para suínos nas fases de crescimento e terminação, a casca de café pode substituir apenas 5\% do milho em rações isoenergéticas (Oliveira, 1999). Porém, Oliveira (2001), utilizando a casca de café melosa em rações para suínos em terminação, concluiu que a casca de café possui baixos valores de digestibilidade e balanço energético quando comparada ao milho, o que pode reduzir o desempenho dos suínos em terminação.

Neste contexto, o objetivo neste trabalho foi determinar a composição química da casca de café melosa e seca, os coeficientes de digestibilidade, os nutrientes digestíveis em diferentes granulometrias, bem como avaliar níveis de inclusão da casca de café melosa sobre o desempenho e as características da carcaça de suínos nas fases de crescimento e terminação e sua viabilidade econômica.

\section{Material e Métodos}

Foram conduzidos dois experimentos, um de digestibilidade e outro de desempenho, avaliando as cascas de café melosa (CM) e seca (CS) obtidas na agroindústria COCAMAR. As cascas de café foram moídas em peneiras de 2,5 mm (CM2 e CS2) e de 4,0 mm(CM4 e CS4).

O experimento I foi constituído de dois ensaios de digestibilidade, um para a fase de crescimento e outro para a fase de terminação, nos quais foram utilizados 15 suínos híbridos comerciais, machos castrados, com $45,7 \pm 4,12 \mathrm{~kg}$ e $77,5 \pm 6,28 \mathrm{~kg}$ de peso inicial, respectivamente. O ensaio de digestibilidade na fase de crescimento teve duração de 25 dias, divididos em dois períodos de 12 dias (sete dias de adaptação e cinco dias de coleta total de fezes) com um dia de intervalo entre períodos. A digestibilidade na fase de terminação foi realizada apenas com a CM4 em 12 dias, sendo sete dias de adaptação e cinco dias de coleta total de fezes.

Foi formulada uma ração referência (RR), à base de milho e farelo de soja, calculada para atender às exigências indicadas pelo NRC (1998). Na fase de crescimento, foram avaliadas a CM2, CM4, CS2 e CS4. Na fase de terminação, foi avaliada apenas a CM4, por ter apresentado os melhores coeficientes de digestibilidade na fase de crescimento. As cascas de café substituíram, com base na MS, 25\% da RR.

As rações foram fornecidas em duas refeições diárias: $60 \%$ às 8 h e $40 \%$ às $16 \mathrm{~h}$. A quantidade total diária foi estabelecida de acordo com o consumo na fase de adaptação e baseada no peso metabólico ( $\left.\mathrm{PV}^{0,75}\right)$ de cada unidade experimental. Após cada refeição, foi fornecida água no comedouro, na proporção de $2,5 \mathrm{~mL} / \mathrm{g}$ de ração, calculada para cada unidade experimental, para evitar o excesso de consumo de água.

Os suínos foram alojados individualmente em gaiolas para ensaios metabólicos, “tipo PEKAS”, instaladas em uma sala de metabolismo com ambiente não controlado. As temperaturas médias pela manhã e tarde foram 23,6 e $29,6^{\circ} \mathrm{C}$, respectivamente.

Foi adotado o método de coleta total de fezes e urina, utilizando-se $2 \%$ de $\mathrm{Fe}_{2} \mathrm{O}_{3}$ como marcador fecal para indicar o início e final das coletas. As fezes produzidas foram coletadas uma vez ao dia, acondicionadas em sacos plásticos e armazenadas em congelador a $-18^{\circ} \mathrm{C}$. Posteriormente, o material foi homogeneizado, seco em estufa de ventilação 
forçada $\left(55^{\circ} \mathrm{C}\right)$ e moído para a realização de análises laboratoriais.

As análises dos alimentos e das fezes foram realizadas segundo os procedimentos descritos por Silva \& Queiroz (2002). A determinação da granulometria dos alimentos foi realizada segundo métodos descritos por Zanotto \& Bellaver (1996) e os teores de energia bruta das rações e das fezes, por meio de calorímetro adiabático (Parr Instrument Co.).

Os coeficientes de digestibilidade da matéria seca (CDMS), energia bruta (CDEB), proteína bruta (CDPB), matéria orgânica (CDMO), fibra bruta (CFB), FDN (CDFDN), FDA (CDFDA) e hemicelulose (CDH) foram calculados conforme Moreira et al. (1994). Aplicou-se a fórmula de Matterson et al. (1965) para obtenção dos nutrientes digestíveis das cascas de café.

Com o objetivo de avaliar diferenças entre os coeficientes de digestibilidade das cascas de café, os dados foram submetidos à análise de variância, utilizando-se o pacote estatístico SAEG (UFV, 1997). Foi considerado o esquema fatorial 2 x 2 (duas cascas e duas moagens), com seis repetições por tratamento para a fase de crescimento, adotando-se o seguinte modelo estatístico para a fase de crescimento:

$$
\mathrm{Y}_{i j k}=\mu+\mathrm{C}_{i}+\mathrm{M}_{j}+\mathrm{CM}_{i j}+\mathrm{e}_{i j k}
$$

em que $Y_{i j k}=$ observação na repetição $k$, da casca de café $i$ e da moagem $j ; \mu=$ constante associada a todas as observações; $\mathrm{C}_{i}=$ efeito do tipo de casca de café, sendo $i=\mathrm{CM} \mathrm{e} \mathrm{CS} ; \mathrm{M} j$ = efeito da moagem, sendo $j=2,5$ e 4,0 mm; $\mathrm{CM} i j=$ efeito da interação do tipo de casca de café $\times$ moagem; $\mathrm{e}_{i j k}=$ erro aleatório associado a cada observação.

No experimento II foi avaliada somente a CM4, por ter apresentado os melhores coeficientes de digestibilidade na fase de crescimento. O experimento foi realizado utilizando 40 suínos híbridos comerciais com elevado potencial de produção de carne magra, sendo metade machos castrados e metade fêmeas, com peso inicial de 33,42 $\pm 0,53 \mathrm{~kg}$ (fase de crescimento) e de 59,54 $\pm 4,17 \mathrm{~kg}$ (fase de terminação). Os animais foram alojados em galpões de alvenaria, cobertos com telhas de fibrocimento, divididos em duas alas - cada uma composta por 10 baias.

Os animais foram distribuídos em delineamento experimental em blocos casualizados, com cinco tratamentos, quatro blocos e dois animais por unidade experimental. Os tratamentos consistiram em uma ração testemunha - RT (sem inclusão da casca de café melosa) e quatro rações contendo níveis crescentes de inclusão de casca de café melosa (5, 10, 15 e 20\% de CM4).

As rações foram formuladas de acordo com as recomendações do NRC (1998), sendo isoenergéticas, isoprotéicas, isocalcíticas e isofosfóricas (Tabela 1). As rações e a água foram fornecidas à vontade durante o período experimental.

Utilizaram-se os valores da composição química e energética dos alimentos sugeridos por Rostagno et al. (2000) e os valores de PB (8,76\%) e ED (2498 kcal/kg) da CM4 obtidos no Experimento I na fase de crescimento (Tabelas 2 e 4).

Ao final do período experimental, os animais foram pesados e o consumo total de ração, computado para o cálculo do consumo diário de ração (CDR), ganho diário de peso (GDP) e conversão alimentar (CA). Foram medidas a espessura de toucinho (ET) na posição P2 nas fases de crescimento e terminação e a profundidade de lombo (PL) na fase de terminação, por meio de aparelho de ultra-som. (RENCO, Sono-Grader).

Foram coletadas amostras de sangue, via veia cava anterior, em tubos contendo heparina, ao início e ao final do experimento, para determinação do nitrogênio da uréia plasmática (NUP). Os valores de NUP foram determinados pelo método de Marsh et al. (1965). Os valores de NUP obtidos no início do experimento foram utilizados como covariável para análise do NUP final.

Para verificar a viabilidade econômica da inclusão da casca de café melosa, foram calculados o custo da ração (CR) e o custo da ração por quilograma de peso vivo (CMR), segundo Bellaver et al. (1985). Posteriormente, foram calculados os índices de eficiência econômica (IEE) e de custo (IC), segundo Barbosa et al. (1992).

Para avaliar as características quantitativas de carcaça, foram abatidos 20 animais, sendo quatro por tratamento, que representavam o peso médio final. As carcaças foram avaliadas segundo o Método Brasileiro de Classificação de Carcaça (ABCS, 1973).

Os resultados obtidos para os níveis de inclusão, excluindo a RT (nível 0 de inclusão), foram submetidos à análise de regressão polinomial, de acordo com o seguinte modelo estatístico:

$$
Y i j=\mu+b_{1}(\mathrm{Ni}-\mathrm{N})+\mathrm{b}_{2}(\mathrm{Ni}-\mathrm{N})+e i j,
$$

em que $\mathrm{Yij}=$ valor observado das variáveis estudadas, relativo a cada individuo $j$, recebendo o nível $i$ de CM4; $\mu=$ constante geral; $b_{1}=$ coeficiente de regressão linear do nível de CM4 sobre a variável $\mathrm{Y}$; $\mathrm{b}_{2}=$ coeficiente de regressão quadrático do nível de CM4 sobre a variável Y; $\mathrm{Ni}=$ níveis de CM4 nas rações, sendo $i=5,10,15$ e 20\%; $\mathrm{N}$ = nível médio de CM4 nas rações, eij = erro aleatório associado a cada observação.

Para a comparação dos resultados obtidos com a RT com cada nível de inclusão de casca de café melosa, foi utilizado o teste Dunnett (Sampaio, 1998). As análises estatísticas foram efetuadas utilizando o pacote estatístico SAEG (UFV, 1997). 
Tabela 1 - Composições centesimal e nutricional das rações contendo diferentes níveis de inclusão da casca de café melosa, para suínos nas fases de crescimento e terminação (Experimento II)

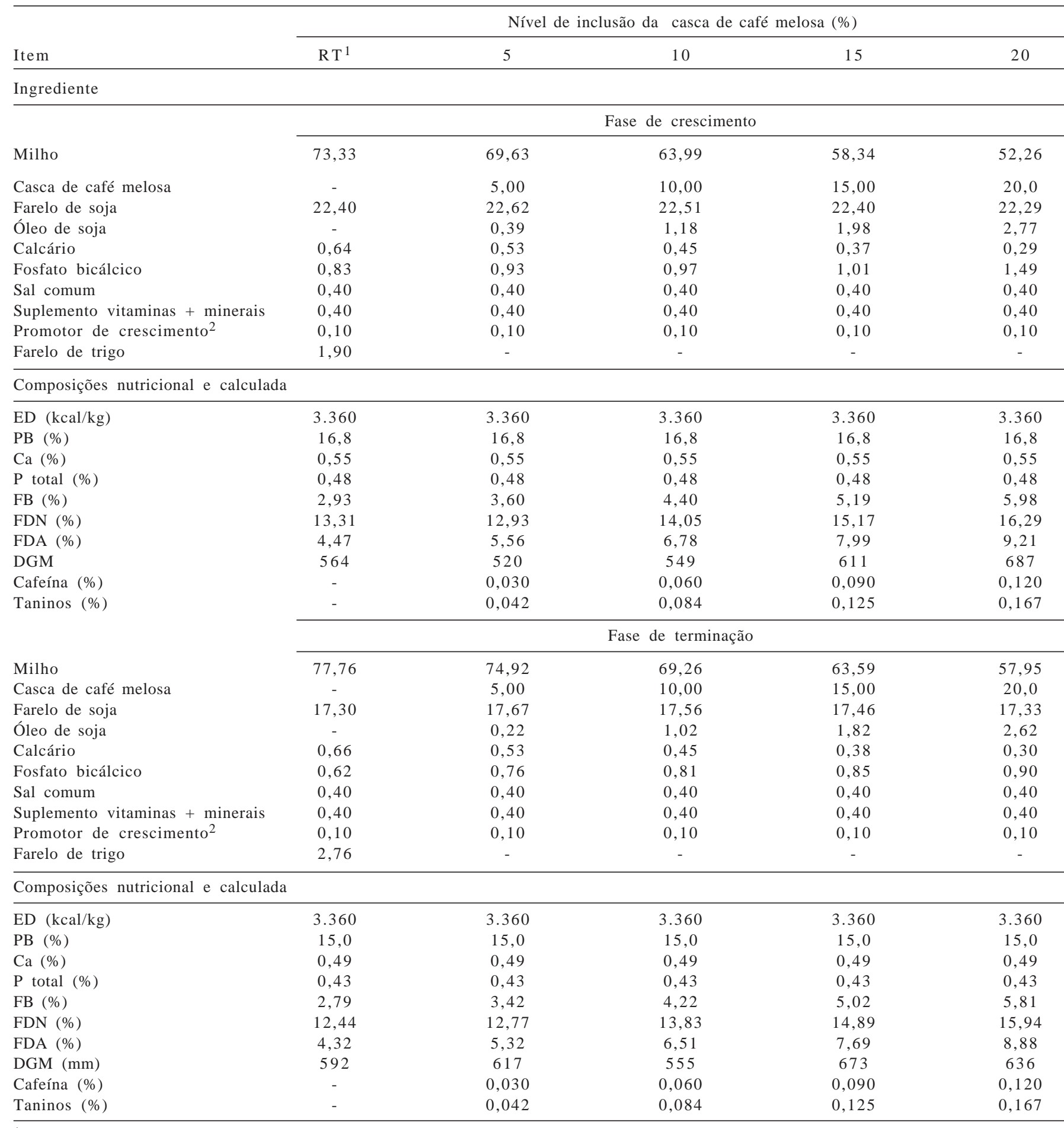

1 Ração testemunha.

2 Lincomicina.

\section{Resultados e Discussão}

A composição química da casca de café melosa (Tabela 2) nas fases de crescimento e terminação apresentou valores de MS superiores (90,37 e 93,51, respectivamente) aos obtidos por Oliveira (2001) e Fialho et al. (1998), utilizando casca de café melosa (85,72 e 87,8\% respectivamente), enquanto os valores de PB foram inferiores $(8,76$ e $7,84 \%)$ aos encontrados por esses autores $(10,47$ e $11,08 \%)$. O valor de fibra bruta (FB) encontrado por Oliveira (2001) foi inferior (17,76\%) e por Fialho et al. (1998), similar (19,3\%) ao verificado neste trabalho. O valor de FDN e FDA apresentado por Oliveira (2001) foi inferior (29,09 e 25,28\%, respectivamente), enquanto 
Teixeira (1999) encontrou valores superiores de MS (91,73\%), PB (12,46\%) e FDN (58,46\%).

Os valores de PB para a casca de café seca encontrados por Ferreira et al (1997), Barcelos et al. (1997), Oliveira (1999), Souza et al. (2001) e Souza et al. (2003) foram superiores $(10,20 ; 10,30 ; 10,20 ; 10,99$ e $9,28 \%$, respectivamente) e por Souza et al. (2004), inferior (6,9\%) aos obtidos neste estudo.

O valor de FB encontrado por Ferreira et al (1997) foi inferior (18,90\%) ao observado nesta pesquisa, ao passo que Barcelos et al. (1997), Fialho et al. (1998), Oliveira (1999), Souza et al. (2001, 2003, 2004) obtiveram valores inferiores para FB, FDN e FDA. As cascas de café apresentaram valores médios de energia bruta semelhantes aos obtidos por Oliveira (1999), Oliveira (2001) e Barcelos et al. (1997). Os valores de Ca e P total foram semelhantes aos reportados por Barcelos et al. (1997).

A variação da composição química das cascas de café varia de acordo com a variedade de café cultivada, condição do solo, região, época de colheita e armazenamento. Segundo Albino \& Silva (1996), as condições de processamento dos subprodutos também podem resultar em grandes variações na composição dos alimentos.

Não houve interações tipos de casca $\times$ grau de moagem para os coeficientes de digestibilidade de MS (CDMS), EB (CDEB), PB (CDPB), MO (CDMO), FB (CDFB) e hemicelulose (CDHEMI). A casca de café melosa apresentou coeficiente de digestibilidade superior $(\mathrm{P}<0,05)$ para todos nutrientes avaliados.

Tabela 2 - Composição nutricional das cascas de café melosa (CM) e seca (CS) (matéria natural)

\begin{tabular}{lccc}
\hline & \multicolumn{2}{c}{ Crescimento } & \multirow{2}{*}{ Terminação } \\
\cline { 2 - 3 } Item & CM & CS & CM4 \\
\hline MS (\%) & 90,37 & 93,21 & 93,51 \\
EB (kcal/kg) & 3738 & 4074 & 3792 \\
PB (\%) & 8,76 & 7,61 & 7,84 \\
Ca (\%) & 0,27 & 0,40 & 0,32 \\
P total (\%) & 0,12 & 0,07 & 0,12 \\
MM (\%) & 5,38 & 4,82 & 6,43 \\
MO (\%) & 77,54 & 81,79 & 81,00 \\
EE (\%) & 1,21 & 0,91 & 1,08 \\
FB (\%) & 18,16 & 43,43 & 18,28 \\
FDN (\%) & 35,58 & 71,25 & 34,38 \\
FDA (\%) & 28,34 & 58,28 & 27,72 \\
Hemicelulose (\%) & 6,68 & 40,50 & 6,66 \\
Lignina (\%) & 7,85 & 13,42 & 5,24 \\
Cafeína (\%) & 0,6 & - & - \\
Taninos (\%) & 0,83 & - & - \\
\hline
\end{tabular}

$\mathrm{CM}=$ casca de café melosa; $\mathrm{CS}$ = casca de café seca; $\mathrm{CM} 4$ = casca de café moída na peneira de $4,0 \mathrm{~mm}$.

${ }^{1}$ Valores segundo análises realizadas no Centro de química de Alimentos e Nutrição Aplicada (ITAL).
Para os coeficientes da FDN e FDA houve interação $(\mathrm{P}<0,05)$, indicando que, para as cascas de café melosa e seca moídas em peneira de 2,5 mm (CM2 e CS2), a digestibilidade não foi influenciada, entretanto, a moagem mais grosseira das cascas (CM4 e CS4) propicia melhor coeficiente de digestibilidade quando se utiliza a casca melosa (Tabela 3).

Avaliando a digestibilidade de diferentes níveis de fibra, Moeser \& Kempen (2002) observaram que a adição de casca de soja na dieta reduz a digestibilidade de MS, energia e N. Quadros (2005), utilizando casca de soja, alimento fibroso como a casca de café, observou coeficiente de digestibilidade (CD) de MS superior aos encontrados neste

Tabela 3 - Coeficientes de digestibilidade aparente da MS (CDMS), EB (CDEB), PB (CDPB), MO (CDMO), FDN (CDFDN), FDA (CDFDA), FB (CDFB) e hemicelulose (CDHEMI) de suínos em crescimento

\begin{tabular}{|c|c|c|c|c|}
\hline \multirow[b]{2}{*}{ Peneira (mm) } & \multicolumn{2}{|c|}{ Casca de café } & \multirow[t]{2}{*}{ Média } & \multirow[t]{2}{*}{ CV (\% } \\
\hline & Melosa & Seca & & \\
\hline & \multicolumn{2}{|c|}{ CDMS } & & \\
\hline 2,5 & 61,43 & 33,66 & 47,55 & \\
\hline 4 & 65,85 & 32,35 & 49,10 & \\
\hline \multirow[t]{2}{*}{ Média } & $63,64 \mathrm{~A}$ & $33,50 \mathrm{~B}$ & 48,57 & 14,70 \\
\hline & \multicolumn{2}{|c|}{ CDEB } & & \\
\hline 2,5 & 66,73 & 30,35 & 48,54 & \\
\hline 4 & 66,83 & 33,02 & 49,92 & \\
\hline \multirow[t]{2}{*}{ Média } & $66,78 \mathrm{~A}$ & $31,68 \mathrm{~B}$ & 49,23 & 15,45 \\
\hline & \multicolumn{2}{|c|}{ CDPB } & & \\
\hline 2,5 & 33,74 & 20,46 & 27,1 & \\
\hline 4 & 45,68 & 12,22 & 28,95 & \\
\hline \multirow[t]{2}{*}{ Média } & $39,71 \mathrm{~A}$ & $16,34 \mathrm{~B}$ & 28,03 & 39,10 \\
\hline & \multicolumn{2}{|c|}{ CDMO } & & \\
\hline 2,5 & 55,04 & 26,67 & 40,85 & \\
\hline 4 & 60,20 & 26,74 & 43,47 & \\
\hline \multirow[t]{2}{*}{ Média } & 57,62A & $26,70 \mathrm{~B}$ & 42,16 & 18,23 \\
\hline & \multicolumn{2}{|c|}{ CDFB } & & \\
\hline 2,5 & 43,81 & 26,63 & 35,22 & \\
\hline 4 & 50,15 & 28,32 & 39,23 & \\
\hline \multirow[t]{2}{*}{ Média } & $46,98 \mathrm{~A}$ & $27,47 \mathrm{~B}$ & 37,22 & 22,50 \\
\hline & \multicolumn{2}{|c|}{ CDFDN } & & \\
\hline 2,5 & $38,68 \mathrm{Ab}$ & $42,30 \mathrm{Aa}$ & 40,49 & \\
\hline 4 & $54,57 \mathrm{Aa}$ & $38,69 \mathrm{Ba}$ & 46,63 & \\
\hline \multirow[t]{2}{*}{ Média } & 46,62 & 40,49 & 43,55 & 9,52 \\
\hline & \multicolumn{2}{|c|}{ CDFDA } & & \\
\hline 2,5 & $33,41 \mathrm{Ab}$ & $29,78 \mathrm{Aa}$ & 31,59 & \\
\hline 4 & $50,29 \mathrm{Aa}$ & $31,25 \mathrm{Ba}$ & 40,77 & \\
\hline \multirow[t]{2}{*}{ Média } & 41,84 & 30,51 & 36,17 & 10,22 \\
\hline & \multicolumn{2}{|c|}{ CDHEMI } & & \\
\hline 2,5 & 71,07 & 31,21 & $51,14 \mathrm{~b}$ & \\
\hline 4 & 85,45 & 33,96 & $59,70 a$ & \\
\hline Média & $78,26 \mathrm{~A}$ & $32,58 \mathrm{~B}$ & 55,42 & 13,86 \\
\hline
\end{tabular}

Médias seguidas de letras diferentes, minúsculas na coluna e maiúsculas na linha, diferem $(P<0,05)$ pelo teste $F$. 
trabalho, entretanto, os valores dos CDEB foram semelhantes aos observados para a casca melosa.

Kutschenko (2004) e Gentilini et al. (1997), estudando casca de soja, obtiveram valores de CDMS semelhantes aos determinados neste estudo, para a casca de café melosa.

$\mathrm{O}$ processo de moagem não influenciou $(\mathrm{P}<0,05)$ a digestibilidade dos nutrientes estudados neste trabalho, o que contraria os resultados obtidos por Quadros (2005), em que a redução no tamanho das partículas dos alimentos fibrosos melhorou a digestibilidade dos nutrientes. Uma possível explicação para estes resultados seria que os dois tipos de peneiras utilizadas não foram suficientes para detectar diferenças entre estas variáveis, o que possivelmente teria sido observado se fossem utilizadas peneiras com furos maiores. Isto sugere que é necessário fazer distinção entre as fibras, em função de sua composição química, que pode influenciar a taxa de passagem e o tempo de fermentação (Tabela 5).

De forma geral, os coeficientes de digestibilidade da CM4 na fase de terminação foram numericamente inferiores aos encontrados com a CM4 na fase de crescimento.

Esta variação pode estar relacionada à composição físico-química e à lignificação dos alimentos. O peso, a idade e a genética dos animais podem influenciar a digestibilidade (Quadros, 2005). Oliveira (2001) e Ferreira (1995), avaliando casca de café melosa, obtiveram valores inferiores de MS digestível (65,65 e 61,02\%), CDPB (68,39 e $65,54 \%$ ) e ED (2799 e 2844 kcal) em relação àqueles obtidos para a casca de café melosa na fase de terminação.

Os valores médios da MS digestível (Tabela 4) e coeficientes de digestibilidade da PB obtidos (Tabela 5) foram inferiores aos valores do milho (80\%) e farelo de soja (90\%), que são alimentos utilizados nas rações de aves e suínos (Fialho et al., 1998). A quantidade de FDN pode ter influenciado estes resultados, porque a fibra é um dos fatores que contribui para a redução da digestibilidade de ingredientes usados em rações de suínos (Noblet \& Perez, 1993).

$\mathrm{Na}$ fase de crescimento, o CDR não diferiu $(\mathrm{P}>0,05)$ entre os níveis 5, 10 e 15\%, comparado à RT, mas foi menor $(\mathrm{P}<0,05)$ para o nível de inclusão $20 \%$, comparado à RT (Tabela 6). Uma possível explicação para a redução do consumo de ração observada com a inclusão de $20 \%$ de CM4 é a quantidade crescente de fibra nesta ração. Anugwa et al. (1989), avaliando os efeitos da fibra dietética e a concentração de proteína em suínos em crescimento, observaram que dietas ricas em fibra diminuem significativamente o consumo e ganho diário de peso quando comparados à ração-referência. Outros fatores
Tabela 4 - Valores digestíveis e de granulometria das cascas melosa (CM) e seca (CS) para suínos em crescimento $(\% \mathrm{MN})$

\begin{tabular}{lcccc}
\hline & \multicolumn{4}{c}{ Valor digestível } \\
\cline { 2 - 5 } & CM2 & CM4 & CS2 & CS4 \\
\hline MS digestível (\%) & 55,51 & 59,51 & 31,37 & 30,15 \\
ED digestível (kcal/kg) & 2.494 & 2.498 & 1.236 & 1.345 \\
PB digestível (\%) & 2,96 & 4,00 & 1,56 & 0,93 \\
MO digestível (\%) & 42,68 & 46,68 & 21,81 & 21,87 \\
FB digestível (\%) & 7,96 & 9,11 & 11,57 & 12,30 \\
FDN digestível (\%) & 13,76 & 19,42 & 30,14 & 27,57 \\
FDA digestível (\%) & 9,47 & 14,25 & 17,36 & 18,21 \\
Hemicelulose digestível (\%) & 4,29 & 5,16 & 12,64 & 13,75 \\
DGM $^{1}(\mu \mathrm{m})$ & 620 & 621 & 381 & 586 \\
\hline
\end{tabular}

${ }^{1}$ Diâmetro geométrico médio.

Tabela 5 - Coeficientes de digestibilidade aparente, nutrientes digestíveis e diâmetro geométrico médio (DGM) da casca de café melosa (CM4) com suínos em terminação (\%MN)

\begin{tabular}{lc}
\hline Coeficiente de digestibilidade & CM4 (\%) \\
\hline MS & 59,82 \\
EB & 53,01 \\
PB & 21,53 \\
MO & 45,19 \\
FB & 29,88 \\
FDN & 54,71 \\
FD A & 30,59 \\
Hemicelulose & 83,62 \\
Nutriente digestível & \\
MS digestível (\%) & 55,94 \\
ED (kcal/kg) & 2,010 \\
PB digestível (\%) & 1,69 \\
MO digestível (\%) & 36,60 \\
FB digestível (\%) & 5,46 \\
FDN digestível (\%) & 18,81 \\
FDA digestível (\%) & 8,48 \\
Hemicelulose digestível (\%) & 10,33 \\
DGM ${ }^{1}(\mu \mathrm{m})$ & 612 \\
\hline
\end{tabular}

${ }^{1}$ Diâmetro geométrico médio.

que podem ter influenciado a redução do consumo são os taninos e a cafeína (Tabela 1), uma vez que estes fatores têm sabor amargo e podem influenciar a digestibilidade e modificar a palatabilidade (Magalhães et al., 2000). A variação de efeitos dos taninos pode ser atribuída em parte à variedade, origem e ao tipo de tanino utilizado na alimentação (Mehansho et al., 1987).

Foi observada redução linear do GDP com o aumento dos níveis de inclusão da casca melosa (Tabela 6) na fase de crescimento. No entanto, essa variável foi semelhante $(\mathrm{P}>0,05)$ entre os níveis de inclusão, quando comparados à RT. A redução observada pode ser atribuída ao aumento do teor de fibra, visto que existe interação da fibra $\times$ demais nutrientes, causando decréscimo na utilização do nitrogênio 
e da energia, além de aumentar a taxa de passagem (Calver, 1991).

A CA foi semelhante $(\mathrm{P}>0,05)$ entre os níveis de inclusão e a RT, resposta esperada, pois foi adicionado óleo às rações contendo CM4 para torná-las isoenergéticas. Apesar de a redução linear do GDP ser conseqüência da diminuição numérica do consumo $(\mathrm{P}>0,05)$, este fato não interferiu na CA entre os níveis de inclusão. Estes resultados de desempenho, de forma geral, são similares aos encontrados por Oliveira (1999), que verificou piora do CDR, GDP e CA, com a inclusão da casca de café seca.

Na fase de crescimento, assim como na fase de terminação, foi observada menor espessura de toucinho no ponto $\mathrm{P} 2$, medidos in vivo, para todos os tratamentos contendo CM4, comparados à RT.

Na fase de terminação, o CDR dos diferentes níveis de inclusão foi semelhante $(\mathrm{P}>0,05)$ aos da $\mathrm{RT}$, porém reduziu linearmente com o aumento dos níveis de inclusão da casca melosa (Tabela 6). Os fatores antinutricionais (cafeína e taninos) presentes na CM4 podem ter sido responsáveis por estes resultados, pois podem ter prejudicado a palatabilidade da ração. Oliveira (2001), trabalhando com casca de café melosa para suínos em terminação com cinco níveis de inclusão (0, 5, 10, 15 e 20\%), não encontrou diferença para o CDR quando comparado à RT.

O GDP e a CA não apresentaram diferença $(\mathrm{P}>0,05)$ entre a RT e os níveis de 5,10 e $15 \%$, mas foi pior $(\mathrm{P}<0,05)$ que a RT e o nível de $20 \%$. Por outro lado, houve piora linear da CA para cada aumento do nível de inclusão da casca de café melosa. De forma semelhante, Oliveira (2001) observou piora do GDP para cada unidade percentual de casca de café melosa adicionada à ração, o que resultou em piora na CA. Por outro lado, Quadros (2005) utilizando diferentes níveis de inclusão de casca de soja (0, 4, 8, 12 e 16\%), um alimento fibroso como a casca de café, não obteve diferenças para as variáveis de desempenho.

Analisando os níveis de inclusão da CM4, o GDP apresentou regressão quadrática (GDP = 0,59223 + 0,04698X $-0,002788 X^{2}$ ), sendo o melhor valor para esta variável obtido com 8,43\% de inclusão da casca de café.

Os valores de ET dos tratamentos com CM4, de forma semelhante ao crescimento, foram inferiores aos da RT. Por outro lado, os valores de profundidade de lombo não apresentaram diferença $(\mathrm{P}>0,05)$ entre os níveis de inclusão, nem entre estes e a RT. Estes resultados indicam que a utilização da CM4 na ração diminui o teor de gordura da carcaça de suínos.

Não houve efeitos dos níveis de inclusão da CM4 sobre o NUP na fase de crescimento e terminação. O teste Dunnett não evidenciou diferença $(\mathrm{P}>0,05)$ entre os níveis de inclusão da CM4, comparados à RT. Isto indica que a qualidade protéica das rações contendo CM4 não foi pior que a RT, o que corrobora os resultados obtidos para a profundidade de lombo (Tabela 6). Estes resultados podem indicar que as rações contendo CM4 foram adequadas em termos de balanço de aminoácidos, o que propiciou deposição de carne semelhante para todos os tratamentos.

Na comparação dos resultados de características de carcaça entre as rações contendo CM4 (5, 10, 15 e 20\%), apenas as variáveis peso de carcaça quente e peso de pernil

Tabela 6 - Consumo diário de ração (CDR), ganho diário de peso (GDP), conversão alimentar (CA), espessura de toucinho na P2 (ET- P2), profundidade de lombo e nitrogênio da uréia plasmática (NUP) dos suínos nas fases de crescimento e terminação alimentados com níveis crescentes de inclusão de casca de café melosa (CM4) nas rações

\begin{tabular}{|c|c|c|c|c|c|c|c|c|}
\hline Item & \multicolumn{5}{|c|}{ Nível de inclusão casca de café melosa (\%) } & $\mathrm{CV}^{2}$ & Dunnet $^{3}$ & $\operatorname{Reg}^{4}$ \\
\hline & \multicolumn{5}{|c|}{ Crescimento } & & & \\
\hline CDR (kg) & 1,943 & 1,769 & 1,727 & 1,562 & $1,548 *$ & 10,81 & 0,05 & NS \\
\hline GDP (kg) & 0,717 & 0,698 & 0,588 & 0,568 & 0,484 & 19,14 & NS & L: 0,04 \\
\hline CA & 2,708 & 2,591 & 2,998 & 2,859 & 3,237 & 12,32 & NS & NS \\
\hline NUP (mg/dL) & \multicolumn{5}{|c|}{ Terminação } & & & \\
\hline CDR (kg) & 2,648 & 2,666 & 2,627 & 2,393 & 1,892 & 18,18 & NS & L: 0,04 \\
\hline GDP (kg) & 0,767 & 0,751 & 0,804 & 0,650 & $0,424 *$ & 11,50 & 0,01 & Q: 0,01 \\
\hline CA & 3,449 & 3,558 & 3,304 & 3,723 & $4,492 *$ & 12,50 & 0,02 & $\mathrm{~L}: 0,01$ \\
\hline ET - P2 (mm) & 11,63 & $10,50 *$ & $10,12 *$ & $9,12 *$ & $8,37 *$ & 19,69 & 0,02 & $\mathrm{~L}: 0,01$ \\
\hline
\end{tabular}

1 Ração-testemunha; ${ }^{2}$ Coeficiente de variação; ${ }^{3}$ Teste Dunnett; * Valor diferente $(P>0,05)$ em relação à testemunha; 4 Análise de regressão: fase de crescimento, $L=$ efeito linear; GDP = 0,074975 - 0,01323X; Fase de terminação, $L=$ efeito linear; $C D R=3,177275-0,05111 X ; C A=2,6441+0,06441 X$ $\mathrm{Q}=$ efeito quadrático, GDP $=0,59223+0,04698 \mathrm{X}-0,002788 \mathrm{X}^{2}$. 
Tabela 7 - Valores médios peso de carcaça quente (PCQ), rendimento de carcaça quente (RCQ), rendimento de carcaça fria (RCF), espessura de toucinho (ET), comprimento de carcaça $(C C)$, peso de pernil (PP), rendimento do pernil (RP) e área de olhode-lombo (AOL), relação carne:gordura (C:G), peso do intestino grosso (PINT), peso do estômago vazio (PEV) e carne magra de suínos alimentados com dietas contendo níveis crescentes de casca de café melosa (CM4) nas fases de crescimento e terminação

\begin{tabular}{|c|c|c|c|c|c|c|c|c|}
\hline \multirow[b]{2}{*}{ Item } & \multicolumn{5}{|c|}{ Nível de inclusão casca de café melosa (\%) } & \multirow[b]{2}{*}{$\mathrm{CV}^{2}$} & \multirow[b]{2}{*}{ Dunnet $^{3}$} & \multirow[b]{2}{*}{$\operatorname{Reg}^{4}$} \\
\hline & $\mathrm{RT}^{1}$ & 5 & 10 & 15 & 20 & & & \\
\hline PCQ (kg) & 70,58 & 67,69 & 70,23 & 64,69 & 62,25 & 6,81 & NS & $\mathrm{L}: 0,01$ \\
\hline RCF (\%) & 40,48 & 40,54 & 39,95 & 39,67 & 39,41 & 1,88 & NS & NS \\
\hline $\mathrm{ET}(\mathrm{cm})$ & 2,38 & 2,44 & 2,47 & 2,28 & 2,35 & 12,54 & NS & NS \\
\hline $\mathrm{CC}(\mathrm{cm})$ & 90,58 & 89,50 & 91,35 & 89,85 & 89,50 & 2,85 & NS & NS \\
\hline AOL $\left(\mathrm{cm}^{2}\right)$ & 42,22 & 37,30 & 39,17 & 38,10 & 37,19 & 10,82 & NS & NS \\
\hline $\mathrm{C}: \mathrm{G}$ & 0,38 & 0,42 & 0,41 & 0,37 & 0,39 & 14,59 & NS & NS \\
\hline PINT (g) & 1.252 & 1.372 & 1.434 & 1.392 & 1.316 & 9,62 & NS & NS \\
\hline $\operatorname{PEV}(\mathrm{g})$ & 0,464 & 0,421 & 0,487 & 0,489 & 0,458 & 13,45 & NS & NS \\
\hline Carne magra (\%) & 57,79 & 53,62 & 55,69 & 53,87 & 52,17 & 6,78 & NS & NS \\
\hline
\end{tabular}

${ }^{1}$ Ração-testemunha; ${ }^{2}$ Coeficiente de variação; ${ }^{3}$ Teste Dunnett; * Valor diferente $(P>0,05)$ em relação à testemunha; ${ }^{4}$ Análise de regressão: $L=$ efeito linear: $\mathrm{PA}=90,93261-0,5436 \mathrm{X} ; \mathrm{PCQ}=74,1932-0,50768 \mathrm{X}$ e PP $=11,57184-0,086728 X$. NS = Não-significativo: $\mathrm{P} \geq 0,05$.

apresentaram redução linear $(\mathrm{P}<0,01)$ com o aumento do nível de inclusão, quando comparados à RT (Tabela 7). Isto pode ser reflexo da redução quadrática do GDP na fase de terminação. No rendimento de carcaça quente, foi observada piora para os tratamentos contendo CM4 comparados à RT. As demais características não diferiram $(\mathrm{P}<0,05)$ quando comparadas à RT. Resultados semelhantes foram obtidos por Oliveira (2001). Entretanto, Quadros (2005) observou que níveis crescentes de casca de soja promovem redução da espessura de toucinho, do rendimento da carcaça quente e rendimento de carcaça fria. Estes resultados podem ser atribuídos à substituição de alimentos ricos em energia por alimentos menos energéticos e ricos em fibra, o que acarreta menor ingestão e, conseqüente- mente, influi no desempenho e nas características da carcaça, tornando-as mais magras.

Redução significativa da área de olho-de-lombo, do peso da carcaça e peso de órgãos digestivos foram observados por Anugwa et al. (1989), exceto o estômago, que aumentou de peso quando suínos foram alimentados com níveis altos de fibra, comparados à ração-referência.

O exame macroscópico das lesões do estômago não evidenciou ulcerações gástricas nos suínos alimentados com a RT ou CM4, porque a fibra dietética pode reduzir este tipo de lesões. Esta resposta pode variar, embora não esteja claro qual característica da fibra influencia este fenômeno (Varel \& Yen, 1997). Entretanto, Rainbird \& Low (1986) sugerem que a fração solúvel da fibra é importante

Tabela 8 - Custo do quilograma de ração, custo em ração por quilograma de peso ganho (CR), índice de eficiência econômica (IEE) e índice de custo (IC) de suínos nas fases de crescimento e terminação alimentados com casca de café melosa (CM4)

\begin{tabular}{|c|c|c|c|c|c|c|c|c|}
\hline \multirow[b]{2}{*}{ Item } & \multicolumn{5}{|c|}{ Nível de inclusão casca de café melosa (\%) } & \multirow[b]{2}{*}{$\mathrm{CV}^{2}$} & \multirow[b]{2}{*}{ Dunnet $^{3}$} & \multirow[b]{2}{*}{$\operatorname{Reg}^{4}$} \\
\hline & $\mathrm{RT}^{1}$ & 5 & 10 & 15 & 20 & & & \\
\hline & \multicolumn{5}{|c|}{ Crescimento } & & & \\
\hline Custo da ração, $\mathrm{R} \$ / \mathrm{kg}$ & 0,447 & 0,439 & 0,448 & 0,450 & 0,452 & - & - & - \\
\hline CR, R\$/kg PV ganho & 1,210 & 1,138 & 1,344 & 1,287 & 1,462 & 12,27 & NS & $\mathrm{L}=0,04$ \\
\hline IEE & 94,04 & 100,00 & 84,69 & 88,46 & 77,82 & - & - & - \\
\hline \multirow[t]{2}{*}{ IC } & 106,33 & 100,00 & 118,07 & 113,04 & 128,49 & - & - & - \\
\hline & \multicolumn{5}{|c|}{ Terminação } & \multirow{5}{*}{12,41} & \multirow{5}{*}{0,06} & \multirow{5}{*}{$\mathrm{Q}=0,02$} \\
\hline Custo da ração, $\mathrm{R} \$ / \mathrm{kg}$ & 0,42 & 0,42 & 0,41 & 0,41 & 0,44 & & & \\
\hline CR, R\$/kg PV ganho & 1,448 & $1,476^{*}$ & $1,366^{*}$ & $1,535^{*}$ & $1,967^{*}$ & & & \\
\hline IEE & 94,37 & 92,55 & 100,00 & 89,04 & 69,47 & & & \\
\hline IC & 105,96 & 108,05 & 100,00 & 112,31 & 143,95 & & & \\
\hline
\end{tabular}

${ }^{1}$ Ração-testemunha; ${ }^{2}$ Coeficiente de variação; ${ }^{3}$ Teste Dunnett; * Valor diferente $(P>0,05)$ em relação a testemunha; ${ }^{4}$ Análise de regressão: fase de crescimento, $L=$ efeito linear; $C R=1,08835+0,0183 X ;$ fase de terminação, $Q=$ efeito quadrático, $C R=1,8542-0,1028 X+0,00542 X{ }^{2}$. 
porque ajuda a diminuir a secreção ácida do estômago, evitando estas lesões.

Na fase de crescimento, houve aumento linear $(\mathrm{P}<0,05)$ do CR com a elevação do nível de inclusão de CM. Por outro lado, o CR não apresentou diferença ( $\mathrm{P}>0,05)$ entre os níveis de inclusão comparados à RT. Na fase de terminação, o CR foi influenciado de forma quadrática (CR = 1,8542-0,1028X $\left.+0,00542 X^{2}\right)$, sendo o menor valor obtido com o nível de 9,48\% de inclusão de CM4 (Tabela 8).

Por outro lado, o teste Dunnett indicou que para o CR os níveis de inclusão foram maiores $(\mathrm{P}=0,06)$ quando comparados à RT. Estas respostas são reflexo da necessidade de inclusão de óleo nas rações contendo níveis mais elevados de CM4. Assim, a opção pela utilização da casca de café deve ser tomada em função da relação de preços dos alimentos, principalmente dos alimentos energéticos.

Assim, do ponto de vista econômico, na fase de crescimento a CM4 deve ser utilizada em até 5,0\% de inclusão, enquanto, na fase de terminação pode ser utilizada até $9,5 \%$ de inclusão. Entretanto, Oliveira (1999) considerando os preços da região Sul de Minas Gerais concluiu que a utilização da casca de café em rações para suínos na fase de crescimento e terminação é viável em até 5\% em substituição ao milho.

\section{Conclusões}

Os coeficientes de digestibilidade da casca de café melosa, para suínos em crescimento, são melhores que os da casca seca, independentemente do grau de moagem (peneira 2,5 e 4,0 mm).

Os valores de ED (kcal/kg) da cascas de café melosa e seca, moídas nas granulometrias de 2,5 e 4,0 mm, são 2.494, 2.498, 1.236 e 1.345 , respectivamente.

A casca de café melosa pode ser incluída em níveis de até 5,0 e 9,5\%, nas fases de crescimento e terminação, respectivamente, sem prejudicar o desempenho, sendo economicamente viável, além de produzir carcaças mais magras.

\section{Agradecimento}

À COCAMAR, pela doação das cascas de café utilizadas, bem como à CAPES e ao CNPq, pela concessão de bolsas de estudo.

\section{Literatura Citada}

ASSOCIAÇÃO BRASILEIRA DE CRIADORES DE SUÍNOS - ABCS. Método brasileiro de classificação de carcaça. Estrela: 1973. 17p. (Publicação Técnica, 2).
ALBINO, L.F.T.; SILVA, M.A. Valores nutritivos de alimentos para aves e suínos determinados no Brasil. In: SIMPOSIO INTERNACIONAL SOBRE EXIGÊNCIAS NUTRICIONAIS DE AVES E SUÍNOS, 1996, Viçosa, MG. Anais... Viçosa, MG: Universidade Federal de Viçosa, 1996. p.303-318.

ANUGWA F.O.I.; VAREL, V.H.; DICKSON, J.S. Effects of dietary fiber and protein concentration on growth, feed efficiency, visceral organ weights and large intestine microbial populations of swine. Journal of Nutrition, v.119, n.6, p.879-886, 1989

BARBOSA, H.P.; FIALHO, E.T.; FERREIRA, A.S. et al. Triguilho para suínos nas fases inicial de crescimento, crescimento e terminação. Revista Brasileira de Zootecnia, v.21, n.5, p.827-837, 1992.

BARCELOS, A.F.; ANDRADE, I.F.; Von TIESENHAUSEN, I.M.E.V. et al. Aproveitamento da casca de café na alimentação de novilhos confinados - Resultados do primeiro ano. Revista Brasileira de Zootecnia, v.26, n.6, p.1208-1214, 1997.

BELLAVER, C.; FIALHO, E.T.; PROTAS, J.F.S. et al. Radícula de malte na alimentação de suínos em crescimento e terminação. Pesquisa Agropecuária Brasileira, v.20, n.8, p.967-974, 1985.

CALVER, C.C. Fiber utilization by swine. In: MILLER, D.E.R.; ULLREY, W.; LEWIS, A.J. (Eds.). Swine nutrition. Stoneham: Butterworth-Heinemann, 1991. p.285-296.

FERREIRA E.R.A.; FIALHO E.T.; TEIXEIRA A.S. et al. Avaliação da composição química e determinação de valores energéticos e equação de predição de alguns alimentos para suínos. Revista Brasileira de Zootecnia, v.26, n.3, p.514-523, 1997.

FERREIRA, E.R.A. Composição química e valores de digestibilidade da proteína e energia de alguns alimentos para suínos. Lavras: Universidade Federal de Lavras, 1995. 50p. Dissertação (Mestrado em Produção Animal) Universidade Federal de Lavras, 1995.

FIALHO E.T.; LIMA J.A.; SILVEIRA, P.R. et al. Avaliação de digestibilidade dos nutrientes de alguns alimentos através de ensaios metabólicos com suínos. In: REUNIÃO DA SOCIEDADE BRASILEIRA DE ZOOTECNIA, 35., 1998, Botucatu. Anais... São Paulo: Sociedade Brasileira de Zootecnia, 1998. p.330-332, 1998.

GENTILINI, F.P.; LIMA, G.J.M.M.; RUTZ, F. et al. Valores de energia da casca de soja crua e tostada obtidos com suínos. In: CONGRESSO BRASILEIRO DE VETERINÁRIOS ESPECIALISTAS EM SUÍNOS. ABRAVES, 8., 1997, Foz do Iguaçu. Anais... Paraná: ABRAVES, 1977. p.375-376.

KUTSCHENKO, M. Efeito de diferentes graus de moagens da casca de soja sobre a digestibilidade dos nutrientes e o desempenho de suínos na fase inicial. Maringá: Universidade Estadual de Maringá, 2004. 40p. Dissertação (Mestrado em Zootecnia) - Universidade Estadual de Maringá, 2004.

MAGALHÃES, P.C.; RODRIGUES, W.A.; DURÃES, F.M.O. Tanino no grão de sorgo: bases fisiológicas e métodos de determinação. Concórdia: Centro Nacional de Pesquisa de Milho e Sorgo EMBRAPA, 2000. 13p. (Circular Técnica, 27)

MARSH, W.H.; FINGERHUT, B.; MILLER, H. Automated and manual direct methods for determination of the determination of blood urea. Clinical Chemistry, v.11, n.6, p.624-627, 1965.

MATTERSON, L.D.; POTTER, L.M.; STUTZ, M.W. et al. The metabolizable energy of feed ingredients for chickens. Storrs: Connecticut University of Connecticut, Agricultural Experiment Station, v.7, n.1, p.11-14, 1965. (Research Report)

MEDEIROS, S.L.S.; SANTIAGO, G.S.; VELOSO, J.A.F. Fibra composição química e seu efeito na nutrição de suínos. Belo Horizonte: Escola Veterinária UFMG, 1988. p.15-22. (Caderno Técnico, 26).

MEHANSHO, H.; BUTLER, L.G.; CARLSON, D.M. et al. Dietary tannins and prolinerich proteins: interactions, induction and defense mechanisms. Annual Review of Nutrition, v.7, p.423-440, 1987. 
MOESER, A.J.; KEMPEN T. Dietary fiber level and xilanase affect nutrient digestibility and excreta characteristics in grower pigs. Raleigh: College of Agriculture \& Life Science. Department of Animal Science, 2002. (Annual Swine Report). 5p.

MOREIRA, I.; ROSTAGNO, H.S.; COELHO, D.T. et al. Determinação dos coeficientes de digestibilidade, valores energéticos e índices de controle de qualidade do milho e da soja integral processados pelo calor. Revista Brasileira de Zootecnia, v.23, p.916-929, 1994.

NATIONAL RESEARCH COUNCIL - NRC. Nutrient requirements of swine. 10.ed. Washington, D.C.: National Academy of Science, 1998. 189p.

NIELSEN, E.K.; INGVARTSEN, K.L. Effect of cereal type, disintegration method and pelleting on stomach content, weight and ulcers and performance in growing pigs. Livestock Production Science, v.66, p.271-282, 2000.

NOBLET, J.; PEREZ, J.M. Prediction of digestibility of nutrients and energy values of pigs diets from chemical analysis. Journal of Animal Science, v.71, n.2, p.3389-3398, 1993.

OLIVEIRA S.L. Avaliação da casca de café em rações para suínos em terminação. Lavras: Universidade Federal de Lavras, 2001. 74p. Dissertação (Mestrado em Zootecnia) Universidade Federal de Lavras, 2001.

OLIVEIRA, V. Casca de café em rações isoenergeticas para suínos em crescimento e terminação (Digestibilidade e desempenho). Lavras: Universidade Federal de Lavras, 1999. 61p. Dissetação (Mestrado em Zootecnia) - Universidade Federal de Lavras, 1999.

QUADROS, A.R.B. Avaliação nutricional da casca de soja, nas formas integral ou moída, ensilada ou não, para suínos nas fases de crescimento e terminação. Maringá: Universidade Estadual de Maringá, 2005. 64p. Tese (Doutorado em Zootecnia) - Universidade Estadual de Maringá, 2005.

RAINBIRD, A.L.; LOW A.G. Effect of various types of dietary fiber on gastric emptying in growing pigs. British Journal Nutrition, v.55, p.87-98, 1986.

ROSTAGNO, H.S.; ALBINO, L.F.T. ; DONZELE, J.L. et al. Tabelas brasileiras para aves e suínos: composição de alimentos e exigências nutricionais. Viçosa, MG: Universidade Federal de Viçosa, 2000. 141p.

UNIVERSIDADE FEDERAL DE VIÇOSA - UFV. SAEG- Sistema de analises estatísticas e genéticas. Versão 7.1. Viçosa, MG: 1997. 150p (Manual do usuário).

SAMPAIO, I.B.M. Estatística aplicada à experimentação animal. Belo Horizonte: Universidade Federal de Minas Gerais, 1998. p.221.

SILVA, D.J.; QUEIROZ, A.C. Análise de alimentos: métodos químicos e biológicos. 3.ed. Viçosa, MG: Universidade Federal de Viçosa, 2002. p.235.

SOUZA, A.L.; GARCIA, R.; PEREIRA, O.G. et al. Composição químico bromatológica da casca de café tratada com amônia anidra e sulfeto de sódio. Revista Brasileira de Zootecnia, v.30, n.3, p.983-991, 2001.

SOUZA, A.L.; SALGADO, F.; GARCIA, R. et al. Valor nutritivo da silagem de capim-elefante (Pennisetum purpureum Schum) com diferentes níveis de casca de café. Revista Brasileira de Zootecnia, v.32, n.4, p.828-833, 2003.

SOUZA, A.L.; GARCIA, R.; BERNARDINO, F.S. et al. Casca de café em dietas de carneiros: consumo e digestibilidade. Revista Brasileira de Zootecnia, v.33, n.6, p.2170-2176, 2004.

SPRING [1996]. Integrating remote sensing and GIS by objectoriented data modeling. Disponível em: http: www.dpi.inpe.br/ geopro/trabalhos/spring.pdf. Acesso em: 22/10/2005.

TEIXEIRA, M.N.M. Determinação da degradabilidade in situ das diferentes frações da casca de três cultivares de café (Coffea arábica. L.). Lavras: Universidade Federal de Lavras, 1999. 44p. Dissertação (Mestrado em Zootecnia) - Universidade Federal de Lavras, 1999.

VAREL, V.H.; YEN J.T. Microbial perspective on fiber utilization by swine. USDA-ARS, U.S. Meat Animal Research Center. Journal of Animal Science, v.75, p.2715-2722, 1997.

ZANOTTO, D.L.; BELLAVER, C.N. Métodos de determinação da granulometria de ingredientes para o uso em rações de suínos e aves. Concórdia: CNPSA-EMBRAPA, 1996. p.15. (Comunicado Técnico, 215). 